\title{
The Combined Human Genotype of Truncating TTN and RBM20 Mutations Is Associated with Severe and Early Onset of Dilated Cardiomyopathy
}

\author{
Anna Gaertner ${ }^{1,2} \mathbb{D}^{1}$, Julia Bloebaum ${ }^{1,2}$, Andreas Brodehl ${ }^{1,2} \oplus$, Baerbel Klauke ${ }^{1,2}$, Katharina Sielemann ${ }^{1,2}$, \\ Astrid Kassner ${ }^{1,2}{ }^{,}$Henrik Fox ${ }^{1}{ }^{(}$, Michiel Morshuis ${ }^{1}$, Jens Tiesmeier ${ }^{1,2}{ }^{2}$ Uwe Schulz ${ }^{1}$, Ralph Knoell ${ }^{3,4}{ }^{1}$, \\ Jan Gummert ${ }^{1}$ and Hendrik Milting ${ }^{1,2, *}$
}

check for updates

Citation: Gaertner, A.; Bloebaum, J.; Brodehl, A.; Klauke, B.; Sielemann, K.; Kassner, A.; Fox, H.; Morshuis, M.; Tiesmeier, J.; Schulz, U.; et al. The Combined Human Genotype of Truncating TTN and RBM20 Mutations Is Associated with Severe and Early Onset of Dilated Cardiomyopathy. Genes 2021, 12, 883. https://doi.org/10.3390/genes12060883

Academic Editor: Jeanette Erdmann

Received: 7 May 2021

Accepted: 5 June 2021

Published: 8 June 2021

Publisher's Note: MDPI stays neutral with regard to jurisdictional claims in published maps and institutional affiliations.

Copyright: (c) 2021 by the authors. Licensee MDPI, Basel, Switzerland. This article is an open access article distributed under the terms and conditions of the Creative Commons Attribution (CC BY) license (https:// creativecommons.org/licenses/by/ $4.0 /)$.
1 Herz-und Diabeteszentrum NRW, Universitätsklinikum der Ruhr-Universität Bochum, Klinik für Thorax- und Kardiovaskularchirurgie, Georgstr. 11, D-32545 Bad Oeynhausen, Germany; agaertner@hdz-nrw.de (A.G.); Julia.Bloebaum@gmx.de (J.B.); abrodehl@hdz-nrw.de (A.B.); bklauke@hdz-nrw.de (B.K.); katharina.frey@uni-bielefeld.de (K.S.); akassner@hdz-nrw.de (A.K.); hfox@hdz-nrw.de (H.F.); mmorshuis@hdz-nrw.de (M.M.); jens.tiesmeier@muehlenkreiskliniken.de (J.T.); Uwe.Schulz@helios-gesundheit.de (U.S.); jgummert@hdz-nrw.de (J.G.)

2 Erich und Hanna Klessmann-Institut für Kardiovaskuläre Forschung und Entwicklung, Georgstr. 11, D-32545 Bad Oeynhausen, Germany

3 Bioscience, Cardiovascular, Renal \& Metabolism, BioPharmaceuticals R\&D, AstraZeneca, SE-431 50 Gothenburg, Sweden; ralph.knoell@ki.se

4 Department of Medicine (MedH), Integrated Cardio Metabolic Centre (ICMC), Heart and Vascular Theme, Karolinska Institute, SE-171 77 Stockholm, Sweden

* Correspondence: hmilting@hdz-nrw.de; Tel.: +49-57-3197-3510

\begin{abstract}
A major cause of heart failure is cardiomyopathies, with dilated cardiomyopathy (DCM) as the most common form. Over 40 genes are linked to DCM, among them TTN and RBM20. Next Generation Sequencing in clinical DCM cohorts revealed truncating variants in TTN (TTNtv), accounting for up to $25 \%$ of familial DCM cases. Mutations in the cardiac splicing factor RNA binding motif protein 20 (RBM20) are also known to be associated with severe cardiomyopathies. TTN is one of the major RBM20 splicing targets. Most of the pathogenic RBM20 mutations are localized in the highly conserved arginine serine rich domain (RS), leading to a cytoplasmic mislocalization of mutant RBM20. Here, we present a patient with an early onset DCM carrying a combination of (likely) pathogenic TTN and RBM20 mutations. We show that the splicing of RBM20 target genes is affected in the mutation carrier. Furthermore, we reveal $R B M 20$ haploinsufficiency presumably caused by the frameshift mutation in RBM20.
\end{abstract}

Keywords: cardiomyopathy; mutation; RBM20; TTN; haploinsufficiency

\section{Introduction}

Dilated cardiomyopathy (DCM) is one of the most common causes of heart failure (HF), with an estimated prevalence of 1 in 200-500 people and the most common indication for heart transplantation (HTx) [1-3]. DCM is defined by left-ventricular chamber dilatation in combination with systolic dysfunction [4]. More than 40 genes are linked to the etiology of DCM [5,6].

RBM20 is a cardiomyopathy-associated gene (MIM \#613172), which is predominantly expressed in striated muscle with highest expression in the heart [7-10]. RBM20-associated DCM is highly penetrant and clinically aggressive. Furthermore, it is characterized by an early onset and an increased risk for malignant ventricular arrhythmias [11,12]. RNA binding motif protein 20 (RBM20) belongs to the serine and arginine rich (SR) like proteins. It contains domains, which are also characteristic for other splicing factors like the ribonucleic acid recognition motif (RRM) and an RS domain, which are highly conserved 
between orthologues and are essential for nuclear retention of RBM20 [13-15]. As a major splicing regulator of the TTN-transcripts, RBM20 influences the myocardial isoform composition of the giant sarcomeric protein titin $[8,13]$. The RBM20-dependent aberrant splicing of TTN contributes to the DCM phenotype of RBM20 mutation carriers. RBM20 controls tissue-specific isoform expression of several other cardiac genes, including genes encoding $\mathrm{Ca}^{2+}$ - and ion-handling proteins such as $C A M K 2 D$ and $R Y R 2[8,13]$. Parikh et al. identified two regions in $R B M 20$ (in exons 9 and 11) which are genetic hotspots for cardiomyopathy associated mutations [12]. Most of the pathogenic RBM20 mutations are localized in the highly conserved RS domain of the protein [16]. Other cardiomyopathy associated mutations were found in the Glu-rich region of the protein [10,16]. Although there are several reports of nonsense or frameshift variants in RBM20 associated with DCM or left ventricular non-compaction cardiomyopathy (LVNC), the pathomechanism of these mutations remains unclear [17-25].

TTN encodes the giant sarcomere protein titin which plays important roles in structure and function of cardiac and skeletal sarcomeres [26,27]. TTN is established as a DCMassociated gene [28-30], with truncating variants in TTN (TTNtvs) being responsible for $15-25 \%$ of genetic DCM cases [31-33].

In this study, we identified, in an index patient with DCM and the need for the implantation of a total artificial heart (TAH), a missense mutation and a mutation leading to a preliminary stop codon in the genes RBM20 (p.Gly603Arg and p.Glu792GlyfsTer9) as well as in TTN (p.Glu8271Gln and p.Lys23669Ter). The patient showed aberrant myocardial splicing of TTN and RYR2. TTN and RYR2 splicing were normal in the patient's father and cousin who also had DCM but carried only the TTN mutations. Quantitative real-time polymerase chain reaction (qRT-PCR) revealed reduced RBM20 mRNA expression in the explanted myocardium of the index patient and RNA-sequencing showed a reduced frequency of the mutant allele. Here, we report for the first time that a frameshift mutation in RBM20 leads to RBM20 haploinsufficiency resulting in consequence in a splicing deficiency of its splicing targets. Furthermore, we show that a combination of (likely) pathogenic TTN and RBM20 mutations leads to a severe cardiac phenotype.

\section{Materials and Methods}

\subsection{Clinical Description of the Patients}

All probands underwent comprehensive cardiac examinations at the Heart and Diabetes Centre NRW (Bad Oeynhausen, Germany), including 12-lead electrocardiogram, echocardiography, and a coronary angiogram if indicated. Diagnosis of DCM was based on previously described diagnostic criteria [34].

Index patient IV.3 (Figure 1) received his diagnosis of DCM at the age of 27 years. He was listed for heart transplantation (HTx) with 34 years and received a total artificial heart (TAH) at the same age. Orthotopic HTx was performed at the age of 35 years. The patient's father (III.2, Figure 1) was also diagnosed with DCM and received a left ventricular assist device (LVAD) with 41 years. HTx was performed with 42 years. The patient's mother (III.3) has arterial hypertension and showed intermittent atrial fibrillation. She has signs of a septal hypertrophy but fulfills no further cardiomyopathy criteria. The cousins of the index patient (IV.8 and IV.9, Figure 1) were diagnosed with DCM. IV.8 received an extracorporeal membrane oxygenation (ECMO) and a LVAD at the age of 23 years. Both monozygotic twins had a history of drug abuse (amphetamines, tetrahydrocannabinol).

For an overview on the clinical baseline characteristics see Table S1.

\subsection{Genetic Analyses}

Molecular genetic analyses were performed after oral and written informed consent. The local ethics committee of the Ruhr-University Bochum (Bad Oeynhausen) approved the study protocol (Reg.-No. 2018-330). The index patient (IV.3) and his cousin (IV.8) were screened for variants in 174 genes by panel sequencing using the TruSight ${ }^{\mathrm{TM}}$ Cardio gene panel (Illumina, San Diego, CA, USA) as previously described [10]. Briefly, DNA was 
isolated from blood using standard techniques (High Pure PCR Template Preparation $\mathrm{Kit}^{\circledR}$, Roche Diagnostics $\mathrm{GmbH}$, Mannheim, Germany) and prepared for cardiac gene enrichment re-sequencing on a MiSeq ${ }^{\circledR}$ next generation sequencing system according to manufacturer's instructions (TruSight ${ }^{\mathrm{TM}}$ Rapid Capture Sample Preparation Kit, Illumina). VariantStudio ${ }^{\mathrm{TM}}$ v3.0 (Illumina) was used for variant annotation. Variants of interest were verified by Sanger sequencing (BigDye ${ }^{\circledR}$ Terminator v1.1 Cycle Sequencing Kit, ABI PRISM ${ }^{\circledR} 3500$ genetic analyzer, Applied Biosystems, Foster City, CA, USA). The parents of the index patient (III.2 and III.3) were genetically screened for variants found in IV.3 by Sanger sequencing. Variant classification followed the guidelines of the American College for Medical Genetics and Genomics (ACMG) [35].
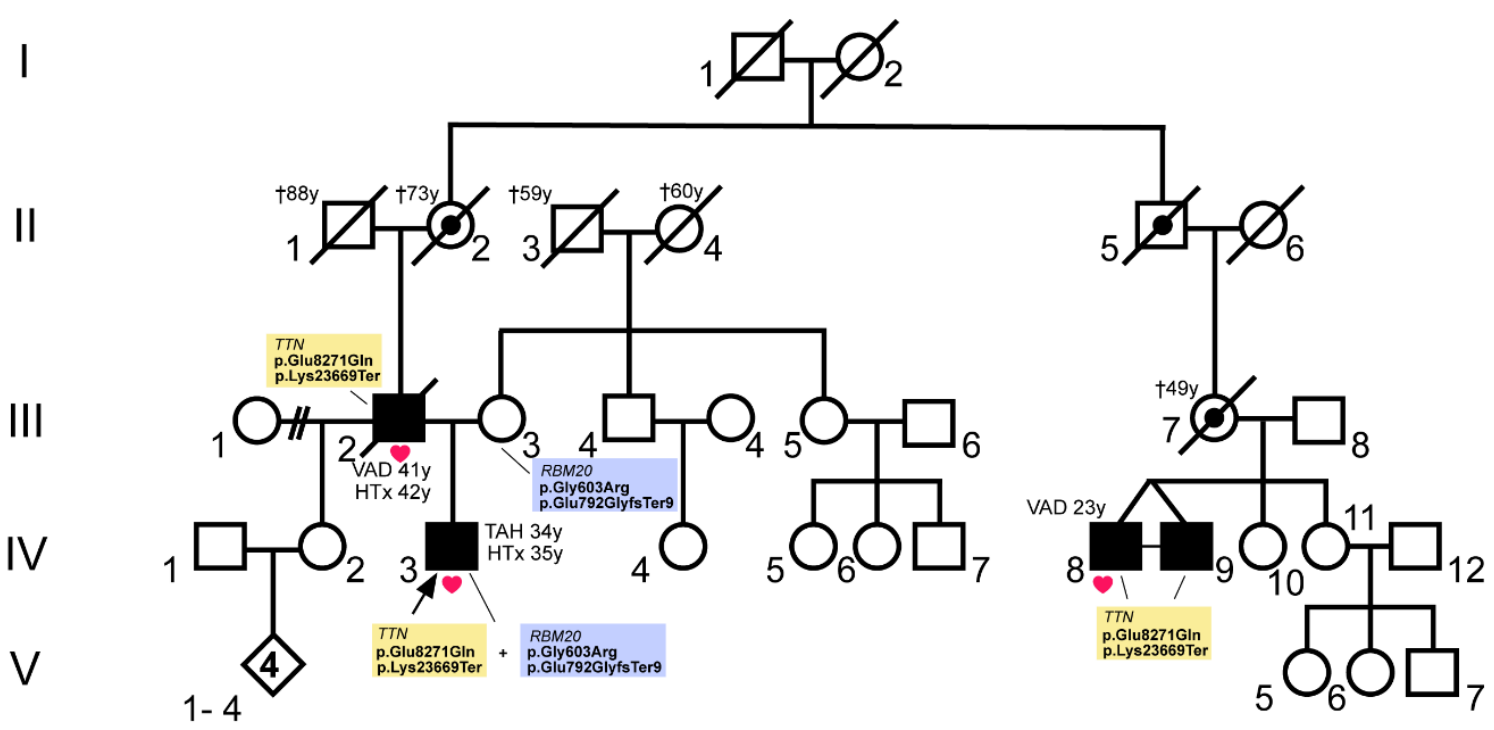

Figure 1. Pedigree of a cardiomyopathy family with (likely) pathogenic RBM20 and TTN mutations. Circles represent females, squares males, slash denotes deceased. The index patient (IV.3) is marked with an arrow. Available myocardial tissue of patients with end-stage heart failure, who received heart transplantation (HTx) or mechanical circulatory support (left ventricular assist device (VAD) or total artificial heart (TAH)) were indicated with red heart symbols. Affected members with dilated cardiomyopathy (DCM) are shown in black and obligate mutation carriers of the TTN mutations are marked with a dot. The age of the patients in years (y) at the time of HTx, VAD- or TAH implantation or at the time of death ( $\dagger$ ) is specified. The respective genotypes of the analyzed patients are shown in the figure.

\subsection{Preparation of Myocardial Tissue}

Myocardial tissue samples from the left ventricle (Biobank of the Heart and Diabetes Center NRW, Bad Oeynhausen, approved by the ethics committee of the Ruhr-University Bochum, registry No. 21/2013) were gained from the probands' explanted heart or during implantation of a LVAD. Samples were immediately snap-frozen in liquid nitrogen and stored at $-80^{\circ} \mathrm{C}$. Written consent for using their explanted myocardial tissue for research and to publish these data in anonymous form was given by all patients. This study conforms to the principles outlined in the Declaration of Helsinki [36].

\subsection{Isolation of Total RNA}

Total RNA was isolated from $30 \mathrm{mg}$ of left ventricular myocardium using a commercial kit (RNeasy, Qiagen, Hilden, Germany) as previously reported [37]. Purity and RNA integrity were verified by agarose gel electrophoresis.

\subsection{Quantitative Real Time Polymerase Chain Reaction}

Reverse transcription of myocardial RNA was performed as described previously [10], with $250 \mathrm{ng}$ of total RNA and 50 units of the enzyme Superscript II (ThermoFisher Scientific, Waltham, MA, USA). For relative quantification of RBM20, TTN, and RYR2 mRNA 
$2 \mu \mathrm{L}$ of the reverse transcription reaction was used. As a housekeeping gene, HPRT1 was used [38]. The measurements were performed in quintuplicates at the StepOnePlus ${ }^{\mathrm{TM}}$ realtime PCR system (ThermoFisher Scientific, Waltham, MA, USA). For relative quantification, the comparative cycle threshold method $(\triangle \Delta C T)$ of the StepOneTM software (v2.0, ThermoFisher Scientific) was used [39]. Primer sequences and PCR conditions were previously described [10]. The $R Y R 2$ splice variant ratio corresponds to the ratio of the $R Y R 2$ splice variant with an additional 24 bp exon against the regular $R Y R 2$ splice variant. The TTN splice variant ratio corresponds to the ratio of TTN-N2B-splice variant to total TTN.

\subsection{Plasmid Construction}

Human RBM20 wildtype cDNA (c.385-3684) was cloned in-frame with an enhanced yellow fluorescent protein tag into the plasmid pEYFP-N1 (Takara Bio, Mountain View, CA, USA) as previously described [10]. The RBM20 variant p.Gly603Arg was introduced by the QuikChange ${ }^{\circledR}$ Lightning Site-Directed Mutagenesis Kit (Agilent Technologies, Santa Clara, CA, USA) according to the manufacturer's instructions. For the generation of the RBM20 p.Glu792GlyfsTer9 the truncated fragment was amplified from the wildtype RBM20 with the following primers (5'-GAATTCATGTCCCAGCCTCTCTTCAATC- $3^{\prime} ; 5^{\prime}$ GGATCCGGTCCGGATGGGGGTGTCTGCTTTCCCCGCAGCCTGGC-3') and inserted into pEYFP-N1 via EcoRI and BamHI restriction sites. RBM20-encoding parts of all generated plasmids were verified by Sanger sequencing (Macrogen, Amsterdam, The Netherlands).

\subsection{Cell Culture and Transient Transfection}

Cell culture and transfections were performed as previously described [10]. Briefly, C2C12 cells (ATCC, Manassas, VA, USA) were cultivated in Dulbecco's Modified Eagle Medium supplemented with 10\% fetal calf serum. Lipofectamine 2000 (ThermoFisher Scientific) was used for cell transfections according to the manufacturer's instructions. Cells were plated $24 \mathrm{~h}$ before transfection on coverglasses coated with $0.02 \%$ collagen R-solution (SERVA electrophoresis, Heidelberg, Germany) and transfected with $750 \mathrm{ng}$ of plasmid DNA in a 24 -well plate at $70-90 \%$ confluence. Cells were fixed and embedded $48 \mathrm{~h}$ after transfection according to Gaertner et al. [10].

\subsection{Immunohistochemistry}

Frozen cardiac tissue was sliced into $5 \mu \mathrm{m}$ sections and treated as previously described [10]. Anti-RBM20 antibody (NBP1-91002, Novus Biologicals, Littleton, CO, USA) and Cy3-conjugated anti-rabbit IgG antibody (C2306, Sigma-Aldrich, St. Louis, MO, USA) were used for RBM20 labelling. For nuclear staining, 4',6-diamidine-2'-phenylindole dihydrochloride (DAPI) solution (Carl Roth, Karlsruhe, Germany) was used. Sections were embedded with Mowiol 4-88 (Carl Roth).

\subsection{Confocal Microscopy}

Image acquisition was performed as previously described [10] with the TCS SP8 confocal microscope (Leica, Wetzlar, Germany).

\subsection{RNA-Sequencing}

RNA-sequencing and read processing were performed as previously described [40]. Briefly, total RNA was isolated from about $\sim 30 \mathrm{mg}$ of myocardial tissue using the RNeasy Mini Kit (Qiagen, Hilden, Germany) and analyzed for RNA integrity number with the RNA 6000 Pico Kit (Agilent Technologies, Santa Clara, CA, USA). The TruSeq Stranded Total RNA Library Prep Kit with Ribo-Zero Gold (Illumina) was applied for RNA sample processing according to the manufacturer's instructions. For final indexed libraries enrichment seven PCR cycles were performed and the indexed libraries were quantified with Qubit dsDNA HS assay kit (ThermoFisher Scientific) and qualified with Bioanalyzer using HS DNA Kit (Agilent Technologies). Equimolar amounts of each library were pooled and sequenced on Illumina HiSeq 3000 (single-end; 50 bp) using sequencing-by-synthesis chemistry v4, 
according to the manufacturer's protocols and as previously described [40]. For each TruSeq RNA library, an average yield of $500 \mathrm{Mb}$ of sequencing data with an average of $96 \%$ reads achieving a quality score $\geq Q 30$ was produced. RNA-sequencing reads were mapped to the hg38 (GRCh38) reference genome sequence using STAR (v2.5.1b) [41]. To analyze RBM20tv-transcript frequency, BAM files were loaded into integrated genome viewer software (IGV_2.8.6, Broad Institute, Cambridge, MA, USA). At the corresponding RBM20 genomic position, the number of transcripts with or without the variant was analyzed.

\section{Results}

3.1. A Combination of Truncating RBM20 and TTN Variants Was Identified in a Patient with Severe DCM

We have identified a combination of truncating RBM20 (NM_001134363) and TTN (NM_001267550) mutations in a German patient with a severe DCM (Figure 1). Besides both truncating mutations, the patient (IV.3) carries missense variants on each of the mutated alleles. He has inherited the TTN mutations p.Glu8271Gln (c.24811G > C) and p.Lys23669Ter (c.71005A > T) from his father (III.2, Figure 1) who also suffered from DCM. The RBM20 mutations p.Gly603Arg (c.1807G > A) and p.Glu792GlyfsTer9 (c.2374dup) were inherited from the mother (III.3, Figure 1) who has arrhythmias but no cardiomyopathy. Due to the maternal and paternal inheritance pattern it is clear that the two TTN or RBM20 variants are localized on the same allele. Two cousins of the patient (IV.8 and IV.9) were also diagnosed with an early onset DCM. One of the monozygotic twins was genotyped and was also carrier of the TTN mutations p.Glu8271Gln and p.Lys23669Ter. Cardiac tissue was available from three mutation carriers (III.2, IV.3, and IV.8, Figure 1).

The RBM20 mutation p.Gly603Arg (rs558674954) has a minor allele frequency (MAF) of 0.00027 in GnomAD [42] and is classified as likely benign in ClinVar [43]. RBM20 p.Glu792GlyfsTer9, which results in a frameshift and a subsequent premature termination codon is not listed in GnomAD. Although there are several reports of truncating RBM20 mutations associated with cardiomyopathy [17-23], until now it is not completely understood how truncating variants contribute to the pathomechanism. As both RBM20 variants are localized on the same allele, they have to be classified together.

The TTN missense variant p.Glu8271Gln and the nonsense variant p.Lys23669Ter are both not listed in GnomAD [42]. Furthermore, the p.Lys23669Ter variant concerns a constitutively expressed TTN exon in the A-band (https:/ / www.cardiodb.org/titin/index.php). It is known from the literature that truncating TTN mutations lead to a late onset cardiomyopathy in $95 \%$ of the cases [31]. According to the ACMG guidelines [35] the TTN-variant p.Lys23669Ter has to be classified as likely pathogenic (class 4). The missense variant p.Glu8271Gln has to be classified as variant of unknown significance as additional data for this variant are lacking. As both TTN variants are localized on the same allele, we have to classify them together. According to the ACMG guidelines [35], the TTN variant combination has to be classified as likely pathogenic (class 4 ).

\subsection{The Ratio of RYR2- and TTN-Splice Variants Is Altered in the Patient with the RBM20 Mutations}

As previously shown, cardiomyopathy associated RBM20 mutations lead to a missplicing of several cardiac genes, including $T T N$ and $R Y R 2$. Recently, we have established a qRT-PCR-based splicing assay using explanted myocardial tissue to predict the pathogenic impact of RBM20 mutations [10]. Analysis of the myocardial splicing of $R Y R 2$ and TTN revealed aberrant splicing of TTN and $R Y R 2$ in the index patient but not in his relatives carrying only the TTN mutations (Figure 2). The TTN splice variant ratio in the index patient was $0.08 \pm 0.01$ (Figure 2A) which is within the reference range for pathogenic RBM20 mutations (0.03-0.11) as previously described [10]. The TTN splicing ratio of the index patient significantly differed ( $p<0.0001$; one-way analysis of variance (ANOVA) with Dunnett's multiple comparisons test) from the TTN splicing ratio in his relatives who were not carriers of the RBM20 mutation. The TTN splicing in IV.8 (0.58 \pm 0.10$)$ 
and III.2 (0.50 \pm 0.07$)$ (Figure 2A) was outside the reference range for pathogenic RBM20 mutations [10].

A

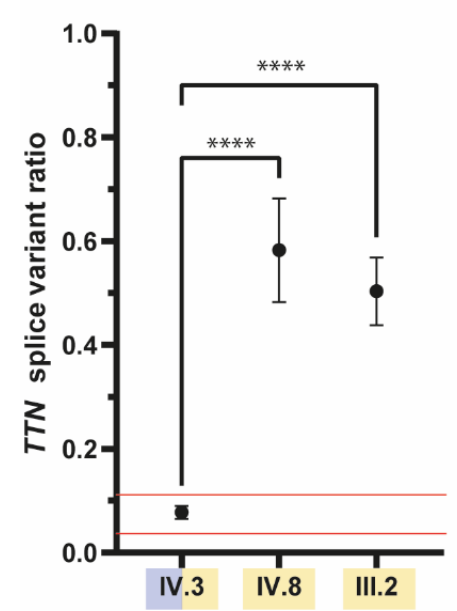

B

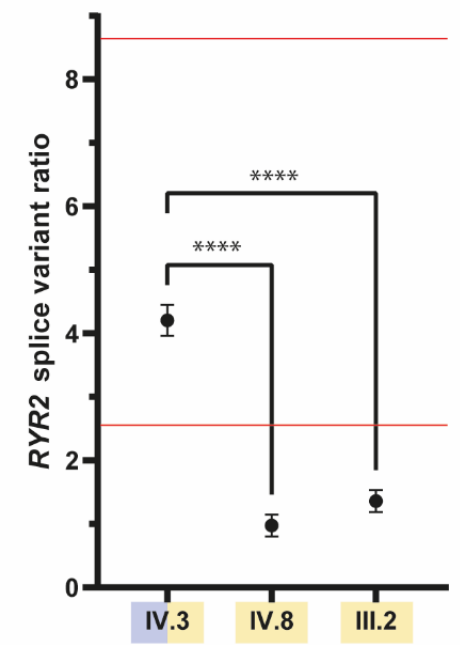

C

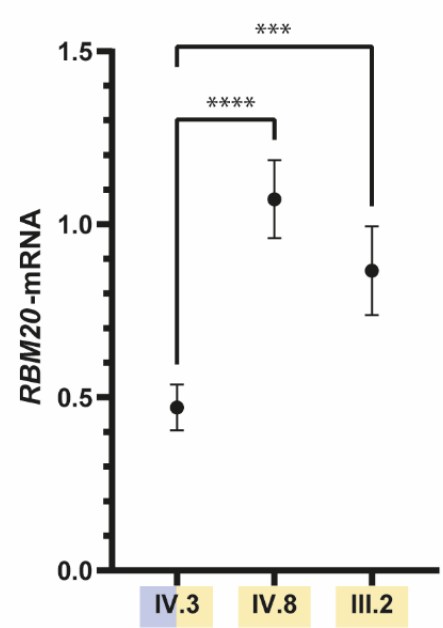

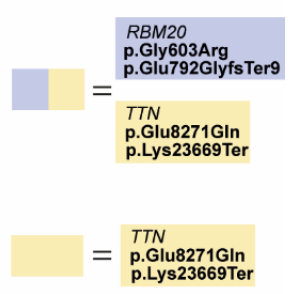

p.Glu8271GIn
p.Lys23669Ter

Figure 2. Quantitative real-time polymerase chain reaction (qRT-PCR) results of (A) TTN- (B) RYR2-splice variant ratios, and (C) relative quantification of RBM20 mRNA. Data from affected family members with available cardiac tissue were measured as technical quintuplicates and are shown as means with standard deviation (SD). For statistical analyses one-way analysis of variance (ANOVA) with Dunnett's multiple comparisons test was used. ${ }^{* * *}=p<0.0001,{ }^{* * *}=p=0.0001$. (A,B) The TTN- and RYR2-splicing in the index patient (IV.3) is significantly different from the splicing in his affected relatives, who are only carriers of the TTN-mutations. The TTN- and RYR2-splicing of IV.3 are within the previously defined reference range [10] for pathogenic RBM20 mutations (red lines). (C) qRT-PCR analysis revealed decreased RBM20 mRNA expression in the RBM20 mutation carrier IV.3 in comparison to his relatives.

Analysis of $R Y R 2$ splice variant ratio (Figure 2B) revealed that the $R Y R 2$ splicing ratio of IV.3 (4.21 \pm 0.25$)$ is within the previously defined reference range for pathogenic mutations (2.55-8.67) [10]. The RYR2 splicing ratio in the index patient significantly differed ( $p<0.0001$; one-way ANOVA with Dunnett's multiple comparisons test) from IV.8 $(0.98 \pm 0.17)$ and III.2 $(1.36 \pm 0.17)$ (Figure 2B) which were outside the reference range for pathogenic RBM20 mutations [10].

In consequence we suggest that besides the likely pathogenic TTN mutations cosegregating with DCM in the family, the mutated RBM20 allele identified in the patient leads to missplicing putatively contributing to the severe phenotype of the index patient IV.3.

\subsection{RBM20-p.Gly603Arg and -p.Glu792GlyfsTer9 Do Not Lead to an Abnormal Cytoplasmic Mislocalization}

Recently, it was shown that the murine Rbm20 and human RBM20 mutants localized within the RS-domain of RBM20 lead to a mislocalization of the protein in the cytoplasm $[10,44,45]$.

In this study, we analyzed the localization of wildtype and mutant RBM20-enhanced yellow fluorescent protein (EYFP) fusion proteins in C2C12 cells and the localization of RBM20 in the explanted tissue of the index patient. Wildtype RBM20 protein localized predominantly in the nuclei (Figure 3). The p.Gly603Arg and p.Glu792GlyfsTer9 RBM20EYFP proteins localized in the nuclei of $\mathrm{C} 2 \mathrm{C} 12$ cells, which is in accordance with the localization of the mutations outside or C-terminal of the conserved RS-domain, as shown previously [10,44]. We analyzed the localization of RBM20 in explanted myocardial tissue of the RBM20-mutation carrier IV.3 (Figure 4). Comparable to the cell culture experiments, mislocalization of RBM20 in the cytoplasm, as it is observable for mutations in the RSdomain (p.Pro638Leu), was excluded. Therefore, it can be suggested that mislocalization 
of the RBM20 mutations p.Gly603Arg and p.Glu792GlyfsTer9 in the cytoplasm is not part of the pathomechanism, leading to the missplicing observed in the index patient IV.3.

\subsection{RBM20-p.Gly603Arg and-p.Glu792GlyfsTer9 Lead to RBM20 Haploinsufficiency in the Index Patient}

We performed RNA-sequencing analysis and revealed reduced levels of the RBM20p.Gly603Arg and p.Glu792GlyfsTer9 allele in the index patient IV.3. However, we detected only expression of RBM20-p.Gly603Arg. However, as both mutations are localized on the same allele, the amount of p.Gly603Arg mRNA species (c.1807G > A exchange) is representative for the mutant allele. RNA-sequencing revealed that the mutant allele with an adenosine at position 1807 of RBM20-mRNA represents $15 \%$ of the mRNA species at this position (Figure 5A). Sequencing of genomic DNA (Figure 5B) proves that the observed allelic misdistribution is not just due to sequencing errors as the heterozygous mutant allele can be observed at a frequency of $46 \%$ in the genomic DNA of the patient.

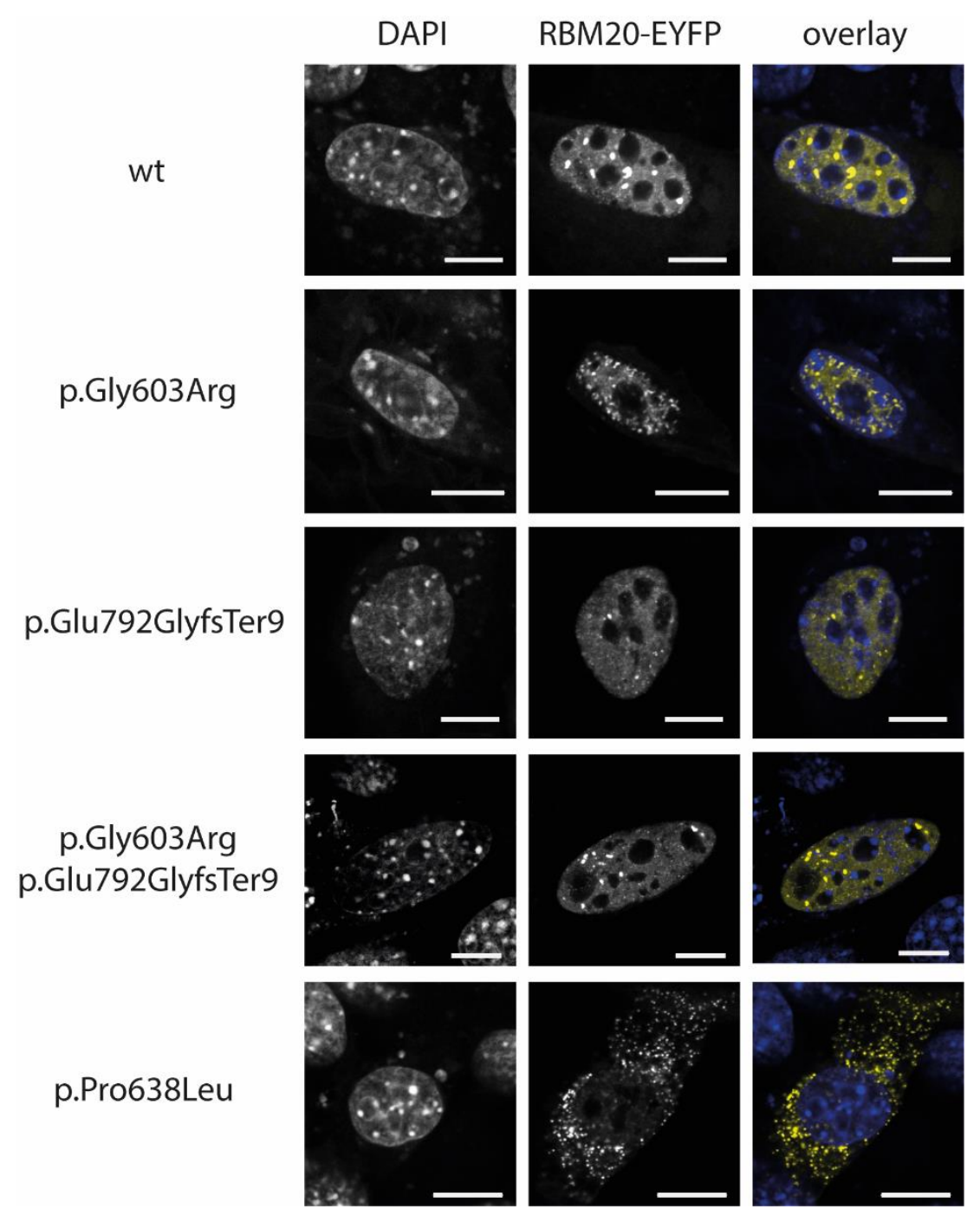

Figure 3. Localization analyses of RNA binding motif protein 20-enhanced yellow fluorescent protein (RBM20-EYFP) transfected C2C12 cells. RBM20 is shown in yellow, and the nuclei were labelled with 4',6-diamidine-2'-phenylindole dihydrochloride (DAPI, blue) in the overlay. EYFP tagged wildtype RBM20 localizes in the nucleus. The mutant forms of RBM20 (p.Gly603Arg and p.Glu792GlyfsTer9) are comparably localized in the nuclei. As described previously [10], only the mutant form RBM20-p.Pro638Leu shows an abnormal cytoplasmic localization. Scale bars $=10 \mu \mathrm{m}$. 


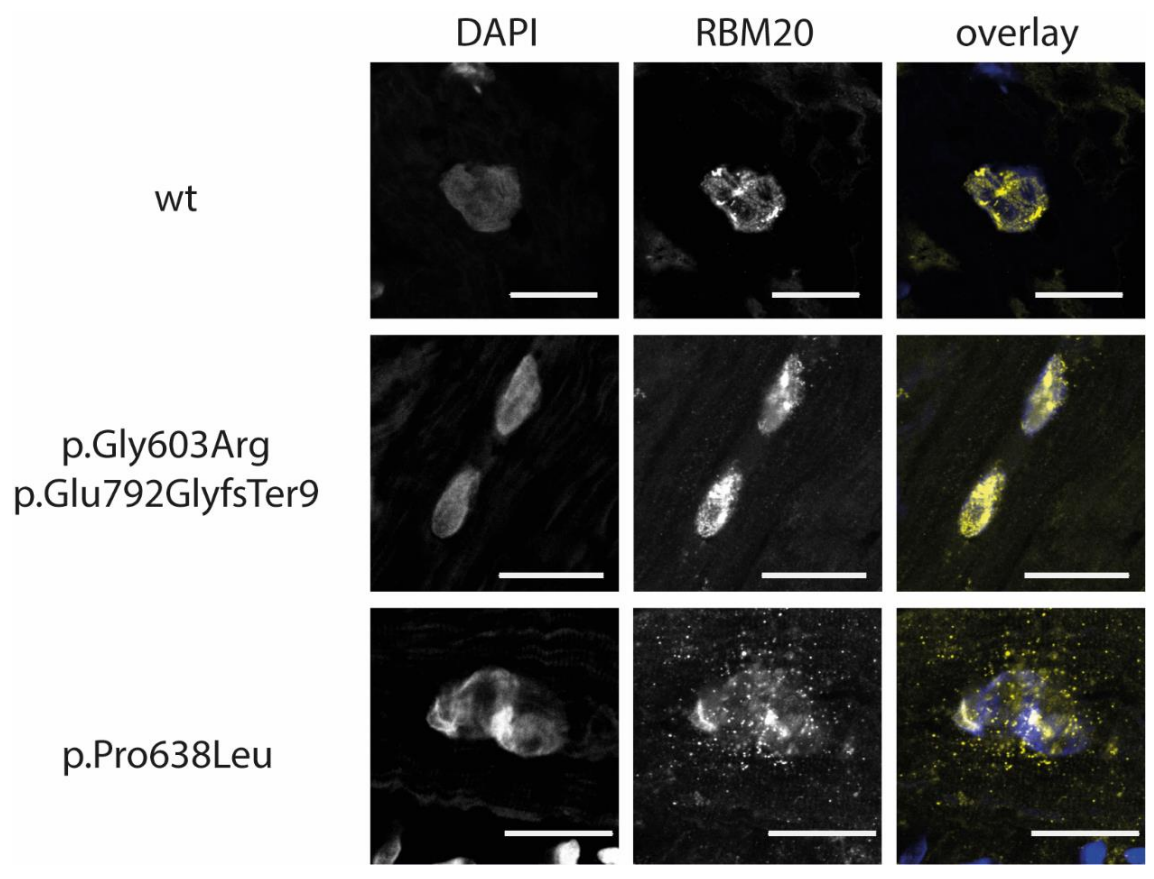

Figure 4. Immunohistochemical analysis of myocardial tissue of cardiomyopathy patients. Representative images of explanted myocardial tissue sections, which were labelled with primary anti RBM20 and Cy3-conjugated secondary antibodies (yellow in the overlay), are shown. Nuclei were labelled with DAPI (blue in the overlay). Tissue from a DCM patient with no RBM20 mutation was used as control. Comparable to the control sample RBM20 is localized in the nuclei in explanted myocardial tissue from IV.3. Sections from a DCM patient with the pathogenic RBM20 mutation p.Pro638Leu were used as a positive control for aberrant cytoplasmic RBM20 localization. Scale bars $=20 \mu \mathrm{m}$.

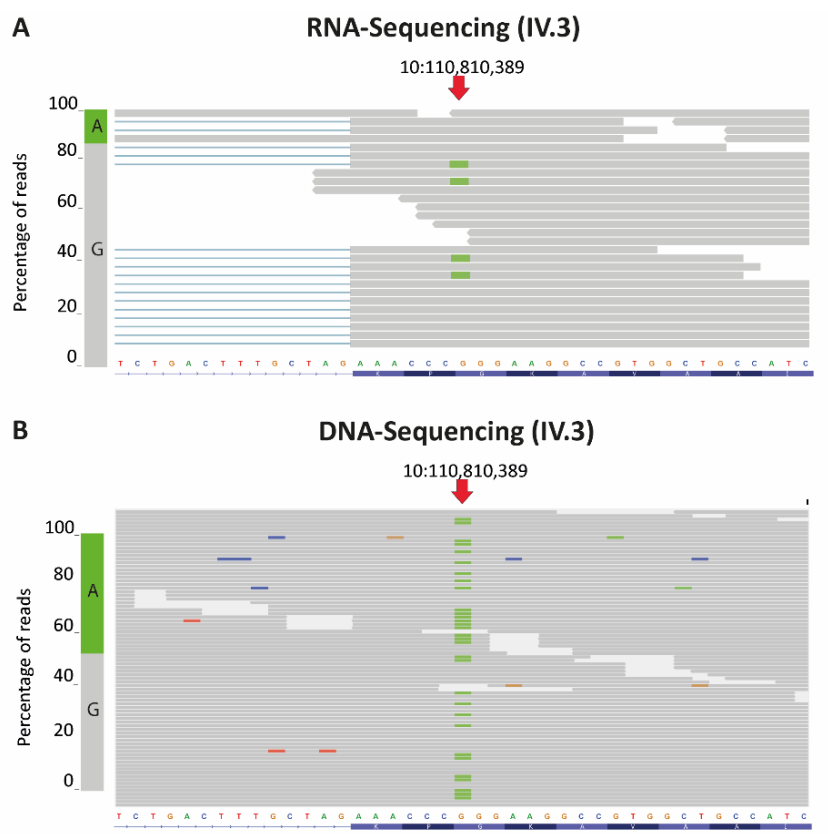

Figure 5. Integrated genome views of exon 8 of RBM20. The chromosomal position corresponding to RBM20 c.1807 is marked with an arrow. Shown are the aligned reads obtained by RNA-sequencing (A) or DNA-sequencing (B) in the respective chromosomal region of index patient IV.3 (RBM20 p.Gly603Arg+p.Glu792fsTer9 and TTN p.Glu8271Gln+ p.Lys23669Ter). At chromosomal position 10:110,810,389 approximately $15 \%$ of the RNA reads (A, bar on the left) represent the mutant form, whereas $46 \%$ of the reads (B, bar on the left) at chromosomal position 10:110,810,389 represent the mutant DNA form. 
qRT-PCR of RBM20-mRNA (Figure 2C) undermined the RNA-sequencing results as $R B M 20$-mRNA content was reduced to a relative quantity (RQ) of $0.47 \pm 0.07$ in the $R B M 20$ mutation carrier compared with an $\mathrm{RQ}$ of $1.07 \pm 0.11$ and $0.87 \pm 0.13$ in his relatives who are carriers of the TTN mutations only.

These results support the conclusion that the missplicing of RBM20 target genes observed in the patient is caused by an RBM20 haploinsufficiency.

\section{Discussion}

Mutations in RBM20 have been associated with DCM already in 2009 [9] and missplicing of several important cardiac genes like TTN was recognized as the potential pathomechanism induced by pathogenic RBM20 mutations [8,13]. Nevertheless, it is likely that several different pathomechanisms might contribute to RBM20-dependent missplicing. It is well known that RBM20 mutations in the highly conserved RS-domain lead to a cytoplasmic mislocalization of the RBM20 protein $[10,44,46,47]$. Besides the cytoplasmic RBM20 granula, which might contribute to the cardiomyopathy phenotype, the absence of the mutant protein from nuclei resulting in a functional RBM20 haploinsufficiency leads to a missplicing in the patients. Currently, it is unclear if the abnormal cytoplasmic $R B M 20$ granula, absence of RBM20 in the nuclei, or a combination of both is part of the underlying pathomechanism.

Besides mutations in the highly conserved RS domain, mutations in the Glu-rich region were identified $[10,16]$. Of note, these mutations do not lead to a cytoplasmic mislocalization of RBM20 but cause missplicing of its splicing targets.

From rodent models it is well known that heterozygous and homozygous $R b m 20$ deficiency leads to a missplicing of Rbm20 target genes [13,47]. In this manuscript, we show for the first time that human $R B M 20$ mutations might also lead to RBM20 haploinsufficiency. qRT-PCR analysis reveals a reduction of $R B M 20-\mathrm{mRNA}$ in the index patient compared to his relatives without any RBM20 mutation. Based on RNA-sequencing data, it can be suggested that the expression of the mutant mRNA is decreased. It is well known that mRNAs carrying a PTC are frequently degraded by nonsense-mediated mRNA decay (NMD) [48-50]. Normally, NMD occurs if a premature termination codon (PTC) is located $\geq 50-55$ nucleotides upstream of an exon-exon junction [51,52]. In RBM20 p.Glu792GlyfsTer9, the insertion of a guanine in exon 9 leads to a frameshift and a PTC approximately 150 nucleotides upstream of the next exon-exon junction, which would be appropriate for the classical $3^{\prime}$ untranslated region exon junction complex dependent NMD. NMD is essential for the elimination of nonfunctional and/or toxic proteins which might result from a transcript with a PTC. Nevertheless, especially in proteins like RBM20, which act in a dose dependent manner $[7,8]$, the cellular function of the protein might be dramatically disturbed by decreased protein levels. Interestingly, we demonstrate here that a decreased RBM20 amount causes missplicing of RBM20 target genes.

As haploinsufficieny can be confirmed for the mutant RBM20 allele of the index patient and this haploinsufficiency obviously leads to missplicing of RBM20 target genes, the ACMG criterion's very strong evidence of pathogenicity (PVS1) is fulfilled $[35,53]$. Accordingly, the combination of RBM20 mutations of the patient can be classified at least as likely pathogenic according to ACMG guidelines [35]. In addition, the pathogenicity of truncating RBM20 mutations is underlined by the low ratio of observed/expected ratio (o/e) for loss of function mutations (pLoF) in the GnomAD [41]. Low o/e values are indicative for a low tolerance for loss of function mutations in one gene. For RBM20, the $90 \%$ confidence interval for pLoF is $0.09-0.29$, which is below the recommended value of 0.35 for its classification as a loss of function variant [42].

It is estimated that truncating TTN mutations (TTNtv) are responsible for up to $25 \%$ of familial DCM cases [31,32,54,55]. TTNtv are especially enriched in A-band titin and affect constitutive exons in end-stage DCM cohorts [32]. The TTN mutation p.Lys23669Ter identified in the patients is localized in the constitutive exon 327, which encodes parts of the A-band titin. It is known that TTNtv commonly leads to a late onset cardiomyopathy with 
an average age for left ventricular diastolic dysfunction of $45 \pm 14$ in male patients [56]. The pathomechanisms of cardiomyopathy caused by TTNtv are not well understood. Based on work with hiPSC-CMs, sarcomere insufficiency was proposed as one of the contributors [57]. Ribosomal and RNA-sequencing revealed that TTN haploinsufficiency and NMD are not part of the pathomechanism in the hearts of TTNtv patients [32,58]. It is believed that additional stress (genetic or environmental) might be necessary for the development of DCM in titin insufficiency [59]. The pathogenic RBM20 mutation combination identified in IV.3 is presumably an additional genetic factor contributing to the pathogenesis of DCM. In patients IV.8 and IV.9, environmental factors might be responsible for the early disease onset as it is well known that consumption of amphetamines might lead to the development of DCM [60-63].

Interestingly, the index patient's mother (III.3), although carrying both RBM20 mutations, shows no signs of DCM. This is in good accordance with previously published data, revealing a more severe disease expression in male RBM20 mutation carriers [64]. Male carriers of pathogenic RBM20 mutations show a significantly younger age and a lower ejection fraction at diagnosis than females [64]. Furthermore, the need for HTx is significantly higher in male mutation carriers [64].

\section{Conclusions}

In our manuscript we reveal that a combination of (likely) pathogenic mutations in TTN and RBM20 leads to a severe cardiac phenotype. Furthermore our results imply that frameshift mutations in $R B M 20$ might lead to RBM20 haploinsufficiency resulting in a splicing deficiency.

Supplementary Materials: The following are available online at https:/ /www.mdpi.com/article/10 .3390/genes12060883/s1, Table S1: Clinical baseline characteristics.

Author Contributions: Conceptualization and methodology were performed by A.G. and H.M. Data curation and analysis were performed by A.G., J.B., A.B., B.K., K.S., A.K., H.F., M.M., J.T., U.S. and R.K. Bioinformatic and Software analysis were performed by K.S. and A.G. Method validation was performed by A.G., J.B., B.K. and A.K. Resources were provided by R.K., J.G., H.M. The original draft of the manuscript was prepared by A.G. The manuscript was reviewed and edited by all coauthors. Project administration and funding acquisition were performed by A.G., R.K., J.G. and H.M. All authors have read and agreed to the published version of the manuscript.

Funding: This research was funded by a Research grant of the Ruhr-University Bochum (FoRUM F842R-2015) and by Erich \& Hanna Klessmann Foundation, Gütersloh, Germany.

Institutional Review Board Statement: The study was conducted according to the guidelines of the Declaration of Helsinki, and approved by the Institutional Ethics Committee of the Ruhr-University Bochum, Bad Oeynhausen) (Reg.-No. 2018-330 and Reg.-No. 21/2013).

Informed Consent Statement: Informed consent was obtained from all subjects involved in the study.

Data Availability Statement: The data that support the findings of this study are available from the corresponding author upon reasonable request.

Acknowledgments: First: we would like to thank the patients for their kind support. Additionally we would like to thank the Erich and Hanna Klessmann-Foundation, Gütersloh, for the financial support. A.G., J.G. and H.M. were additionally supported by the FoRUM Forschungsförderung of the University Bochum (FoRUM F842R-2015).

Conflicts of Interest: The authors declare that there is no conflict of interest. 


\section{References}

1. Hershberger, R.E.; Hedges, D.J.; Morales, A. Dilated cardiomyopathy: The complexity of a diverse genetic architecture. Nat. Rev. Cardiol. 2013, 10, 531-547. [CrossRef] [PubMed]

2. Khush, K.K.; Cherikh, W.S.; Chambers, D.C.; Goldfarb, S.; Hayes, D., Jr.; Kucheryavaya, A.Y.; Levvey, B.J.; Meiser, B.; Rossano, J.W.; Stehlik, J.; et al. The International Thoracic Organ Transplant Registry of the International Society for Heart and Lung Transplantation: Thirty-fifth Adult Heart Transplantation Report-2018; Focus Theme: Multiorgan Transplantation. J. Heart Lung Transpl. 2018, 37, 1155-1168. [CrossRef] [PubMed]

3. Rossano, J.W.; Cherikh, W.S.; Chambers, D.C.; Goldfarb, S.; Hayes, D., Jr.; Khush, K.K.; Kucheryavaya, A.Y.; Toll, A.E.; Levvey, B.J.; Meiser, B.; et al. The International Thoracic Organ Transplant Registry of the International Society for Heart and Lung Transplantation: Twenty-first pediatric heart transplantation report-2018; Focus theme: Multiorgan Transplantation. J. Heart Lung Transpl. 2018, 37, 1184-1195. [CrossRef]

4. McMurray, J.J.; Adamopoulos, S.; Anker, S.D.; Auricchio, A.; Bohm, M.; Dickstein, K.; Falk, V.; Filippatos, G.; Fonseca, C.; Gomez-Sanchez, M.A.; et al. ESC Guidelines for the diagnosis and treatment of acute and chronic heart failure 2012: The Task Force for the Diagnosis and Treatment of Acute and Chronic Heart Failure 2012 of the European Society of Cardiology. Developed in collaboration with the Heart Failure Association (HFA) of the ESC. Eur. Heart J. 2012, 33, 1787-1847. [CrossRef] [PubMed]

5. Brodehl, A.; Ebbinghaus, H.; Deutsch, M.A.; Gummert, J.; Gartner, A.; Ratnavadivel, S.; Milting, H. Human Induced Pluripotent Stem-Cell-Derived Cardiomyocytes as Models for Genetic Cardiomyopathies. Int. J. Mol. Sci. 2019, 20, 4381. [CrossRef]

6. McNally, E.M.; Golbus, J.R.; Puckelwartz, M.J. Genetic mutations and mechanisms in dilated cardiomyopathy. J. Clin. Investig. 2013, 123, 19-26. [CrossRef] [PubMed]

7. Li, S.; Guo, W.; Dewey, C.N.; Greaser, M.L. Rbm20 regulates titin alternative splicing as a splicing repressor. Nucleic Acids Res. 2013, 41, 2659-2672. [CrossRef]

8. Maatz, H.; Jens, M.; Liss, M.; Schafer, S.; Heinig, M.; Kirchner, M.; Adami, E.; Rintisch, C.; Dauksaite, V.; Radke, M.H.; et al. RNA-binding protein RBM20 represses splicing to orchestrate cardiac pre-mRNA processing. J. Clin. Investig. 2014, 124, 3419-3430. [CrossRef] [PubMed]

9. $\quad$ Brauch, K.M.; Karst, M.L.; Herron, K.J.; de Andrade, M.; Pellikka, P.A.; Rodeheffer, R.J.; Michels, V.V.; Olson, T.M. Mutations in ribonucleic acid binding protein gene cause familial dilated cardiomyopathy. J. Am. Coll. Cardiol. 2009, 54, 930-941. [CrossRef] [PubMed]

10. Gaertner, A.; Klauke, B.; Felski, E.; Kassner, A.; Brodehl, A.; Gerdes, D.; Stanasiuk, C.; Ebbinghaus, H.; Schulz, U.; Dubowy, K.O.; et al. Cardiomyopathy-associated mutations in the RS domain affect nuclear localization of RBM20. Hum. Mutat. 2020, 41, 1931-1943. [CrossRef]

11. van den Hoogenhof, M.M.G.; Beqqali, A.; Amin, A.S.; van der Made, I.; Aufiero, S.; Khan, M.A.F.; Schumacher, C.A.; Jansweijer, J.A.; van Spaendonck-Zwarts, K.Y.; Remme, C.A.; et al. RBM20 Mutations Induce an Arrhythmogenic Dilated Cardiomyopathy Related to Disturbed Calcium Handling. Circulation 2018, 138, 1330-1342. [CrossRef]

12. Parikh, V.N.; Caleshu, C.; Reuter, C.; Lazzeroni, L.C.; Ingles, J.; Garcia, J.; McCaleb, K.; Adesiyun, T.; Sedaghat-Hamedani, F.; Kumar, S.; et al. Regional Variation in RBM20 Causes a Highly Penetrant Arrhythmogenic Cardiomyopathy. Circ. Heart Fail. 2019, 12, e005371. [CrossRef]

13. Guo, W.; Schafer, S.; Greaser, M.L.; Radke, M.H.; Liss, M.; Govindarajan, T.; Maatz, H.; Schulz, H.; Li, S.; Parrish, A.M.; et al. RBM20, a gene for hereditary cardiomyopathy, regulates titin splicing. Nat. Med. 2012, 18, 766-773. [CrossRef]

14. Filippello, A.; Lorenzi, P.; Bergamo, E.; Romanelli, M.G. Identification of nuclear retention domains in the RBM20 protein. FEBS Lett. 2013, 587, 2989-2995. [CrossRef] [PubMed]

15. Weeland, C.J.; van den Hoogenhof, M.M.; Beqqali, A.; Creemers, E.E. Insights into alternative splicing of sarcomeric genes in the heart. J. Mol. Cell. Cardiol. 2015, 81, 107-113. [CrossRef]

16. Beqqali, A.; Bollen, I.A.; Rasmussen, T.B.; van den Hoogenhof, M.M.; van Deutekom, H.W.; Schafer, S.; Haas, J.; Meder, B.; Sorensen, K.E.; van Oort, R.J.; et al. A mutation in the glutamate-rich region of RNA-binding motif protein 20 causes dilated cardiomyopathy through missplicing of titin and impaired Frank-Starling mechanism. Cardiovasc. Res. 2016, 112, $452-463$. [CrossRef]

17. Augusto, J.B.; Eiros, R.; Nakou, E.; Moura-Ferreira, S.; Treibel, T.A.; Captur, G.; Akhtar, M.M.; Protonotarios, A.; Gossios, T.D.; Savvatis, K.; et al. Dilated cardiomyopathy and arrhythmogenic left ventricular cardiomyopathy: A comprehensive genotype-imaging phenotype study. Eur. Heart J. Cardiovasc. Imaging 2020, 21, 326-336. [CrossRef] [PubMed]

18. Marschall, C.; Moscu-Gregor, A.; Klein, H.G. Variant panorama in 1385 index patients and sensitivity of expanded next-generation sequencing panels in arrhythmogenic disorders. Cardiovasc. Diagn. Ther. 2019, 9, S292-S298. [CrossRef] [PubMed]

19. Waldmuller, S.; Schroeder, C.; Sturm, M.; Scheffold, T.; Imbrich, K.; Junker, S.; Frische, C.; Hofbeck, M.; Bauer, P.; Bonin, M.; et al. Targeted 46-gene and clinical exome sequencing for mutations causing cardiomyopathies. Mol. Cell. Probes 2015, $29,308-314$. [CrossRef]

20. Gigli, M.; Merlo, M.; Graw, S.L.; Barbati, G.; Rowland, T.J.; Slavov, D.B.; Stolfo, D.; Haywood, M.E.; Dal Ferro, M.; Altinier, A.; et al. Genetic Risk of Arrhythmic Phenotypes in Patients With Dilated Cardiomyopathy. J. Am. Coll. Cardiol. 2019, 74, 1480-1490. [CrossRef] [PubMed] 
21. Refaat, M.M.; Lubitz, S.A.; Makino, S.; Islam, Z.; Frangiskakis, J.M.; Mehdi, H.; Gutmann, R.; Zhang, M.L.; Bloom, H.L.; MacRae, C.A.; et al. Genetic variation in the alternative splicing regulator RBM20 is associated with dilated cardiomyopathy. Heart Rhythm 2012, 9, 390-396. [CrossRef] [PubMed]

22. Liu, S.; Xie, Y.; Zhang, H.; Feng, Z.; Huang, J.; Huang, J.; Hu, S.; Wei, Y. Multiple genetic variants in adolescent patients with left ventricular noncompaction cardiomyopathy. Int. J. Cardiol. 2020, 302, 117-123. [CrossRef]

23. van Waning, J.I.; Caliskan, K.; Hoedemaekers, Y.M.; van Spaendonck-Zwarts, K.Y.; Baas, A.F.; Boekholdt, S.M.; van Melle, J.P.; Teske, A.J.; Asselbergs, F.W.; Backx, A.; et al. Genetics, Clinical Features, and Long-Term Outcome of Noncompaction Cardiomyopathy. J. Am. Coll. Cardiol. 2018, 71, 711-722. [CrossRef]

24. Jorda, P.; Toro, R.; Diez, C.; Salazar-Mendiguchia, J.; Fernandez-Falgueras, A.; Perez-Serra, A.; Coll, M.; Puigmule, M.; Arbelo, E.; Garcia-Alvarez, A.; et al. Malignant Arrhythmogenic Role Associated with RBM20: A Comprehensive Interpretation Focused on a Personalized Approach. J. Pers. Med. 2021, 11, 130. [CrossRef]

25. Gaertner, A.; Klauke, B.; Brodehl, A.; Milting, H. RBM20 mutations in left ventricular non-compaction cardiomyopathy. Pediatr. Investig. 2020, 4, 61-63. [CrossRef] [PubMed]

26. Anderson, B.R.; Granzier, H.L. Titin-based tension in the cardiac sarcomere: Molecular origin and physiological adaptations. Prog. Biophys. Mol. Biol. 2012, 110, 204-217. [CrossRef] [PubMed]

27. Linke, W.A. Titin Gene and Protein Functions in Passive and Active Muscle. Annu. Rev. Physiol. 2018, 80, 389-411. [CrossRef]

28. Siu, B.L.; Niimura, H.; Osborne, J.A.; Fatkin, D.; MacRae, C.; Solomon, S.; Benson, D.W.; Seidman, J.G.; Seidman, C.E. Familial dilated cardiomyopathy locus maps to chromosome 2q31. Circulation 1999, 99, 1022-1026. [CrossRef] [PubMed]

29. Gerull, B.; Atherton, J.; Geupel, A.; Sasse-Klaassen, S.; Heuser, A.; Frenneaux, M.; McNabb, M.; Granzier, H.; Labeit, S.; Thierfelder, L. Identification of a novel frameshift mutation in the giant muscle filament titin in a large Australian family with dilated cardiomyopathy. J. Mol. Med. 2006, 84, 478-483. [CrossRef]

30. Gerull, B.; Gramlich, M.; Atherton, J.; McNabb, M.; Trombitas, K.; Sasse-Klaassen, S.; Seidman, J.G.; Seidman, C.; Granzier, H.; Labeit, S.; et al. Mutations of TTN, encoding the giant muscle filament titin, cause familial dilated cardiomyopathy. Nat. Genet. 2002, 30, 201-204. [CrossRef] [PubMed]

31. Herman, D.S.; Lam, L.; Taylor, M.R.; Wang, L.; Teekakirikul, P.; Christodoulou, D.; Conner, L.; DePalma, S.R.; McDonough, B.; Sparks, E.; et al. Truncations of titin causing dilated cardiomyopathy. N. Engl. J. Med. 2012, 366, 619-628. [CrossRef]

32. Roberts, A.M.; Ware, J.S.; Herman, D.S.; Schafer, S.; Baksi, J.; Bick, A.G.; Buchan, R.J.; Walsh, R.; John, S.; Wilkinson, S.; et al. Integrated allelic, transcriptional, and phenomic dissection of the cardiac effects of titin truncations in health and disease. Sci. Transl. Med. 2015, 7, 270ra276. [CrossRef]

33. Ware, J.S.; Seidman, J.G.; Arany, Z. Shared Genetic Predisposition in Peripartum and Dilated Cardiomyopathies. N. Engl. J. Med. 2016, 374, 2601-2602. [CrossRef]

34. Mestroni, L.; Maisch, B.; McKenna, W.J.; Schwartz, K.; Charron, P.; Rocco, C.; Tesson, F.; Richter, A.; Wilke, A.; Komajda, M. Guidelines for the study of familial dilated cardiomyopathies. Collaborative Research Group of the European Human and Capital Mobility Project on Familial Dilated Cardiomyopathy. Eur. Heart J. 1999, 20, 93-102. [CrossRef]

35. Richards, S.; Aziz, N.; Bale, S.; Bick, D.; Das, S.; Gastier-Foster, J.; Grody, W.W.; Hegde, M.; Lyon, E.; Spector, E.; et al. Standards and guidelines for the interpretation of sequence variants: A joint consensus recommendation of the American College of Medical Genetics and Genomics and the Association for Molecular Pathology. Genet. Med. Off. J. Am. Coll. Med. Genet. 2015, 17, 405-424. [CrossRef]

36. World Medical, A. World Medical Association Declaration of Helsinki: Ethical principles for medical research involving human subjects. JAMA 2013, 310, 2191-2194. [CrossRef]

37. Gaertner-Rommel, A.; Tiesmeier, J.; Jakob, T.; Strickmann, B.; Veit, G.; Bachmann-Mennenga, B.; Paluszkiewicz, L.; Klingel, K.; Schulz, U.; Laser, K.T.; et al. Molecular autopsy and family screening in a young case of sudden cardiac death reveals an unusually severe case of FHL1 related hypertrophic cardiomyopathy. Mol. Genet. Genom. Med. 2019, 7, e841. [CrossRef] [PubMed]

38. Thellin, O.; Zorzi, W.; Lakaye, B.; De Borman, B.; Coumans, B.; Hennen, G.; Grisar, T.; Igout, A.; Heinen, E. Housekeeping genes as internal standards: Use and limits. J. Biotechnol. 1999, 75, 291-295. [CrossRef]

39. Livak, K.J.; Schmittgen, T.D. Analysis of relative gene expression data using real-time quantitative PCR and the 2(-Delta Delta C(T)) Method. Methods 2001, 25, 402-408. [CrossRef]

40. Sielemann, K.; Elbeck, Z.; Gartner, A.; Brodehl, A.; Stanasiuk, C.; Fox, H.; Paluszkiewicz, L.; Tiesmeier, J.; Wlost, S.; Gummert, J.; et al. Distinct Myocardial Transcriptomic Profiles of Cardiomyopathies Stratified by the Mutant Genes. Genes 2020, 11, 1430. [CrossRef] [PubMed]

41. Dobin, A.; Davis, C.A.; Schlesinger, F.; Drenkow, J.; Zaleski, C.; Jha, S.; Batut, P.; Chaisson, M.; Gingeras, T.R. STAR: Ultrafast universal RNA-seq aligner. Bioinformatics 2013, 29, 15-21. [CrossRef]

42. Karczewski, K.J.; Francioli, L.C.; Tiao, G.; Cummings, B.B.; Alföldi, J.; Wang, Q.; Collins, R.L.; Laricchia, K.M.; Ganna, A.; Birnbaum, D.P.; et al. Variation across 141,456 human exomes and genomes reveals the spectrum of loss-of-function intolerance across human protein-coding genes. bioRxiv 2019, 531210. [CrossRef]

43. Landrum, M.J.; Lee, J.M.; Benson, M.; Brown, G.R.; Chao, C.; Chitipiralla, S.; Gu, B.; Hart, J.; Hoffman, D.; Jang, W.; et al. ClinVar: Improving access to variant interpretations and supporting evidence. Nucleic Acids Res. 2018, 46, D1062-D1067. [CrossRef] 
44. Murayama, R.; Kimura-Asami, M.; Togo-Ohno, M.; Yamasaki-Kato, Y.; Naruse, T.K.; Yamamoto, T.; Hayashi, T.; Ai, T.; Spoonamore, K.G.; Kovacs, R.J.; et al. Phosphorylation of the RSRSP stretch is critical for splicing regulation by RNA-Binding Motif Protein 20 (RBM20) through nuclear localization. Sci. Rep. 2018, 8, 8970. [CrossRef] [PubMed]

45. Brodehl, A.; Ebbinghaus, H.; Gaertner-Rommel, A.; Stanasiuk, C.; Klauke, B.; Milting, H. Functional analysis of DES-p.L398P and RBM20-p.R636C. Genet. Med. Off. J. Am. Coll. Med. Genet. 2019, 21, 1246-1247. [CrossRef] [PubMed]

46. Schneider, J.W.; Oommen, S.; Qureshi, M.Y.; Goetsch, S.C.; Pease, D.R.; Sundsbak, R.S.; Guo, W.; Sun, M.; Sun, H.; Kuroyanagi, H.; et al. Dysregulated ribonucleoprotein granules promote cardiomyopathy in RBM20 gene-edited pigs. Nat. Med. 2020, 26, 1788-1800. [CrossRef]

47. Ihara, K.; Sasano, T.; Hiraoka, Y.; Togo-Ohno, M.; Soejima, Y.; Sawabe, M.; Tsuchiya, M.; Ogawa, H.; Furukawa, T.; Kuroyanagi, H. A missense mutation in the RSRSP stretch of Rbm20 causes dilated cardiomyopathy and atrial fibrillation in mice. Sci. Rep. 2020, 10, 17894. [CrossRef]

48. Frischmeyer, P.A.; Dietz, H.C. Nonsense-mediated mRNA decay in health and disease. Hum. Mol. Genet. 1999, 8, 1893-1900. [CrossRef] [PubMed]

49. Zhang, J.; Maquat, L.E. Evidence that the decay of nucleus-associated nonsense mRNA for human triosephosphate isomerase involves nonsense codon recognition after splicing. RNA 1996, 2, 235-243. [PubMed]

50. Popp, M.W.; Maquat, L.E. Organizing principles of mammalian nonsense-mediated mRNA decay. Annu. Rev. Genet. 2013, 47, 139-165. [CrossRef]

51. Nagy, E.; Maquat, L.E. A rule for termination-codon position within intron-containing genes: When nonsense affects RNA abundance. Trends Biochem. Sci. 1998, 23, 198-199. [CrossRef]

52. Thermann, R.; Neu-Yilik, G.; Deters, A.; Frede, U.; Wehr, K.; Hagemeier, C.; Hentze, M.W.; Kulozik, A.E. Binary specification of nonsense codons by splicing and cytoplasmic translation. EMBO J. 1998, 17, 3484-3494. [CrossRef]

53. Abou Tayoun, A.N.; Pesaran, T.; DiStefano, M.T.; Oza, A.; Rehm, H.L.; Biesecker, L.G.; Harrison, S.M.; ClinGen Sequence Variant Interpretation Working, G. Recommendations for interpreting the loss of function PVS1 ACMG/AMP variant criterion. Hum. Mutat. 2018, 39, 1517-1524. [CrossRef]

54. Haas, J.; Frese, K.S.; Peil, B.; Kloos, W.; Keller, A.; Nietsch, R.; Feng, Z.; Muller, S.; Kayvanpour, E.; Vogel, B.; et al. Atlas of the clinical genetics of human dilated cardiomyopathy. Eur. Heart J. 2015, 36, 1123-1135. [CrossRef] [PubMed]

55. Akinrinade, O.; Ollila, L.; Vattulainen, S.; Tallila, J.; Gentile, M.; Salmenpera, P.; Koillinen, H.; Kaartinen, M.; Nieminen, M.S.; Myllykangas, S.; et al. Genetics and genotype-phenotype correlations in Finnish patients with dilated cardiomyopathy. Eur. Heart J. 2015, 36, 2327-2337. [CrossRef] [PubMed]

56. Akhtar, M.M.; Lorenzini, M.; Cicerchia, M.; Ochoa, J.P.; Hey, T.M.; Sabater Molina, M.; Restrepo-Cordoba, M.A.; Dal Ferro, M.; Stolfo, D.; Johnson, R.; et al. Clinical Phenotypes and Prognosis of Dilated Cardiomyopathy Caused by Truncating Variants in the TTN Gene. Circ. Heart Fail. 2020, 13, e006832. [CrossRef]

57. Hinson, J.T.; Chopra, A.; Nafissi, N.; Polacheck, W.J.; Benson, C.C.; Swist, S.; Gorham, J.; Yang, L.; Schafer, S.; Sheng, C.C.; et al. HEART DISEASE. Titin mutations in iPS cells define sarcomere insufficiency as a cause of dilated cardiomyopathy. Science 2015, 349, 982-986. [CrossRef]

58. van Heesch, S.; Witte, F.; Schneider-Lunitz, V.; Schulz, J.F.; Adami, E.; Faber, A.B.; Kirchner, M.; Maatz, H.; Blachut, S.; Sandmann, C.L.; et al. The Translational Landscape of the Human Heart. Cell 2019, 178, 242-260. [CrossRef] [PubMed]

59. Tabish, A.M.; Azzimato, V.; Alexiadis, A.; Buyandelger, B.; Knoll, R. Genetic epidemiology of titin-truncating variants in the etiology of dilated cardiomyopathy. Biophys. Rev. 2017, 9, 207-223. [CrossRef]

60. Won, S.; Hong, R.A.; Shohet, R.V.; Seto, T.B.; Parikh, N.I. Methamphetamine-associated cardiomyopathy. Clin. Cardiol. 2013, 36, 737-742. [CrossRef] [PubMed]

61. Jacobs, L.J. Reversible dilated cardiomyopathy induced by methamphetamine. Clin. Cardiol. 1989, 12, 725-727. [CrossRef]

62. Ito, H.; Yeo, K.K.; Wijetunga, M.; Seto, T.B.; Tay, K.; Schatz, I.J. A comparison of echocardiographic findings in young adults with cardiomyopathy: With and without a history of methamphetamine abuse. Clin. Cardiol. 2009, 32, E18-E22. [CrossRef]

63. Yeo, K.K.; Wijetunga, M.; Ito, H.; Efird, J.T.; Tay, K.; Seto, T.B.; Alimineti, K.; Kimata, C.; Schatz, I.J. The association of methamphetamine use and cardiomyopathy in young patients. Am. J. Med. 2007, 120, 165-171. [CrossRef]

64. Hey, T.M.; Rasmussen, T.B.; Madsen, T.; Aagaard, M.M.; Harbo, M.; Molgaard, H.; Moller, J.E.; Eiskjaer, H.; Mogensen, J. Pathogenic RBM20-Variants Are Associated With a Severe Disease Expression in Male Patients With Dilated Cardiomyopathy. Circ. Heart Fail. 2019, 12, e005700. [CrossRef] 